Original

\title{
Stress distribution in fixed-partial prosthesis and peri-implant bone tissue with different framework materials and vertical misfit levels: a three-dimensional finite element analysis
}

\author{
Ataís Bacchi, Rafael L. X. Consani, Marcelo F. Mesquita, and Mateus B. F. dos Santos \\ Department of Prosthodontics and Periodontics, Piracicaba Dental School, Campinas State University, \\ Piracicaba, SP, Brazil
}

(Received May 13, 2013; Accepted August 3, 2013)

\begin{abstract}
The purpose of this study was to evaluate the influence of superstructure material and vertical misfits on the stresses created in an implant-supported partial prosthesis. A three-dimensional (3-D) finite element model was prepared based on common clinical data. The posterior part of a severely resorbed jaw with two osseointegrated implants at the second premolar and second molar regions was modeled using specific modeling software (SolidWorks 2010). Finite element models were created by importing the solid model into mechanical simulation software (ANSYS Workbench 11). The models were divided into groups according to the prosthesis framework material (type IV gold alloy, silver-palladium alloy, commercially pure titanium, cobalt-chromium alloy, or zirconia) and vertical misfit level $(10 \mu \mathrm{m}, 50 \mu \mathrm{m}$, and $100 \mu \mathrm{m})$ created at one implant-prosthesis interface. The gap of the vertical misfit was set to be closed and the stress values were measured in the framework, porcelain veneer, retention screw, and bone tissue. Stiffer materials led to higher stress concentration in the framework and increased stress values in the retention screw, while in the same circumstances, the porcelain veneer showed lower stress values, and there was no significant difference in stress in the peri-implant bone tissue. A considerable increase in stress concentration was observed in all the structures evaluated within the misfit amplification. The framework material influenced the stress concentration in
\end{abstract}

Correspondence to Dr. Ataís Bacchi, Department of Prosthodontics and Periodontics, Piracicaba Dental School, Campinas State University, Av. Limeira, 901 Piracicaba, SP 13414-903, Brazil

E-mail: atais_bacchi@yahoo.com.br the prosthetic structures and retention screw, but not that in bone tissue. All the structures were significantly influenced by the increase in the misfit levels. (J Oral Sci 55, 239-244, 2013)

Keywords: dental implant; dental prosthesis, implantsupported; biomechanics.

\section{Introduction}

With the advent of osseointegrated dental implants, prosthetic treatment in partially and completely edentulous patients has significantly improved (1). The connection between the osseointegrated implant and peri-implant bone tissue is more rigid in comparison with the resilience of the periodontal ligament of the natural dentition (2). Thus, a passive fit at the implant-prosthesis interface has been suggested to be crucial for the long-term success of osseointegration (3) and to prevent future complications (4). Dimensional changes can occur during clinical and laboratory procedures of prosthesis fabrication as a result of improper clinical techniques or manufacturing defects (2).

Many complications can be caused by misfit in prosthetic frameworks. These complications include biologic effects such as bone deformation and remodeling, microdamage, continual resorption, or even loss of osseointegration (2,5). Mechanical complications include porcelain fracture, screw loosening or fracture, and framework fracture $(2,4)$. Some studies associate these complications with the misfit of the prosthesis $(6,7)$. However, the exact relationship between prosthesis misfit and implant complications is still poorly understood (8).

Distortions that occur during the clinical and technical 
Table 1 Material properties adopted in the study

\begin{tabular}{lcc}
\hline Material & Young's modulus (GPa) & Poisson's ratio \\
\hline Cortical bone (11) & 13.7 & 0.30 \\
Cancellous bone (11) & 1.37 & 0.30 \\
Titanium (implant) (11) & 110 & 0.33 \\
Titanium (screw) (11) & 110 & 0.28 \\
Procera All-Ceran Zirconia (21) & 269 & 0.25 \\
Cobalt-chromium (11) & 218 & 0.33 \\
Commercially pure titanium (11) & 110 & 0.28 \\
Silver-palladium alloy (11) & 95 & 0.33 \\
Type IV gold alloy (11) & 80 & 0.33 \\
Vita VMK 68 (Porcelain veneer) (22) & 70 & 0.19 \\
\hline
\end{tabular}

steps of prosthesis fabrication may hinder the achievement of passive fit. These distortions may occur during the impression procedure, master cast fabrication, wax pattern fabrication, casting, porcelain firing, and tolerance of the different implant components (2). In addition, biologic tolerance has been suggested regarding the presence of misfit $(7,9,10)$; however, there is difficulty in determining these states due to the limitations of these studies and the ethical issues associated with in vivo studies (11).

The materials used in framework fabrication have been suggested to be very important for biomechanical reasons. When loads are applied on the superstructure, stresses are created within them and transferred to the bone-implant interface, implant, and prosthetic components (12). They could influence the survival of the restoration and affect the bone stress distribution around implants (13). Initially, gold alloy was the most frequently used material for framework fabrication, but due to its high cost, alternative alloys were introduced in dentistry, including cobalt-chromium, silver-palladium, and titanium alloys (11). More recently, zirconia frameworks were proposed as an esthetic alternative for the metallic implant framework due to their chemical durability, aesthetics, biocompatibility, minimal plaque accumulation potential, and superior mechanical properties (14), thus solving the corrosion and esthetic limitations of metal alloys (1). These advantages led to an exponential increase in zirconia application as the framework material for dental prosthesis (2).

The stresses on prosthetic structures and bone tissue are not only observed when occlusal loads are applied. Stresses are also created when ill-fitting prostheses are installed $(15,16)$, and the values of these generated stresses vary with the stiffness of the framework material (13). Previous finite element analyses (FEA) were used to evaluate the influence of the increase in vertical misfit in implant-supported fixed prostheses $(8,17)$ and overdenture-retaining bars supported by two implants $(11,18)$. However, controversial results were observed as the misfit amplification caused a considerable increase in stresses in peri-implant bone tissue in implant-supported fixed prostheses and did not influence the stress values in peri-implant bone in overdenture retaining systems. Different framework materials for single crowns (19) fixed-partial prostheses (14) and full arch prostheses (20) were evaluated with respect to the stresses transferred to peri-implant tissue and prosthetic structures; however, the presence of vertical misfit, a clinical possibility, was not considered. The aim of this study was to evaluate the influence of the framework material and different levels of vertical misfit on the stresses created in a partial implant-supported prosthesis (framework and porcelain veneer), retention screw, and peri-implant bone during usage of the prosthesis.

\section{Materials and Methods}

The three-dimensional model was defined based on clinical data taken from a common situation. The posterior part of a severely resorbed jaw (12.7-mm height $\times$ 23.2-mm width, with 1-mm thick cortical bone layer) with two osseointegrated titanium implants (External Hexagonal, cylindrical, 4.0-mm diameter $\times 10-\mathrm{mm}$ length) placed slightly mesially angulated (18 degrees) and parallel to each other in the right second pre-molar and second molar regions, with a distance of $16.1 \mathrm{~mm}$ between them and a metal-ceramic fixed-partial denture (9.1-mm height $\times 18-\mathrm{mm}$ width, with an average ceramic layer of $1.4 \mathrm{~mm}$ ), was modeled using specific 3-D modeling software (SolidWorks 2010, SolidWorks Corp., Concord, MA, USA). The implant thread was removed because, after convergence tests, it was found to be irrelevant to the analysis and caused a significant reduction in elements.

Finite element models were obtained by importing the solid model into mechanical simulation software 


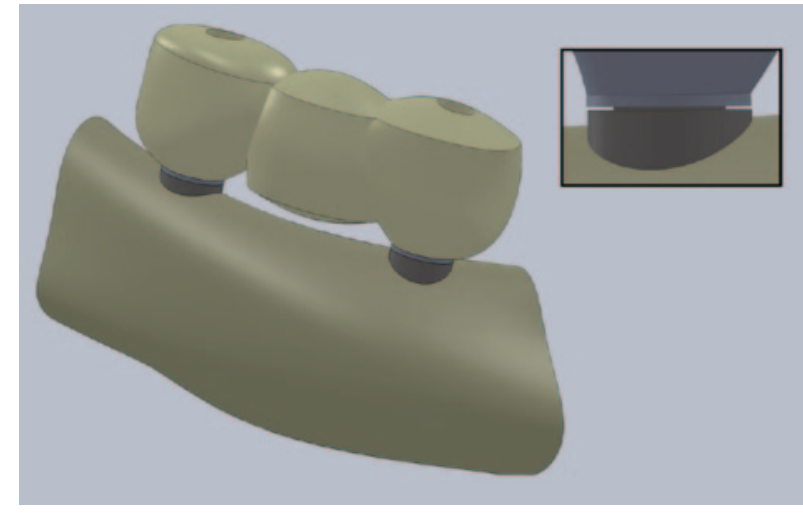

Fig. 1 Configuration of the investigated models.

(ANSYS Workbench 11, Ansys Inc., Canonsburg, PA, USA). The models were divided into groups according to the framework material - type IV gold alloy $(\mathrm{Au})$, silverpalladium alloy (Ag-Pd), commercially pure titanium (Ti), cobalt-chromium alloy (Co-Cr), or zirconia ( $\mathrm{Zr}$ ) - and misfit level $(10 \mu \mathrm{m}, 50 \mu \mathrm{m}$, and $100 \mu \mathrm{m})$ created at the second pre-molar implant-prosthesis interface. All materials used in the models were considered to be isotropic, homogeneous, and linearly elastic. The elastic properties used were taken from the literature (Table 1) $(11,21,22)$.

Model stability was ensured to obtain a reliable model that was regarded as relevant with respect to engineering and clinical aspects (11). The total number of elements and nodes generated in the FE models were 736,750 and 1178,870 for $10 \mu \mathrm{m}, 742,289$ and 1187,188 for $50 \mu \mathrm{m}$, and 725,737 and 1160,223 for $100 \mu \mathrm{m}$ of vertical misfit, respectively. The shape of the element was tetrahedral with 10 nodes. The investigated models showed the configurations presented in Fig. 1. The stability of the model was checked, and particular attention was paid to the refinement of the mesh resulting from the convergence tests at the bone/implant interface.

The base of the mandible was set as the fixed support, the gap of the vertical misfit was set to be closed and data were produced numerically, color-coded, and compared among the models. The maximum principal stress for framework, porcelain veneer, and bone tissue was recorded, since this criterion can be applied for fragile and friable materials; its application in the framework was due to the presence of the zirconia, a material that belongs to ceramic groups. The von Mises stresses were recorded for the prosthetic screw, since this criterion provides maximum deformation energy of a material, especially for rigid and ductile structures such as metals.
Table 2 Maximum principal stress (MPa) in the prosthesis framework

\begin{tabular}{lccc}
\hline \multirow{2}{*}{ Material } & \multicolumn{3}{c}{ Misfit } \\
\cline { 2 - 4 } & $10 \mu \mathrm{m}$ & $50 \mu \mathrm{m}$ & $100 \mu \mathrm{m}$ \\
\hline $\mathrm{Au}$ & 134.97 & 791.47 & $1,649.10$ \\
$\mathrm{Ag}-\mathrm{Pd}$ & 152.94 & 878.52 & $1,841.00$ \\
$\mathrm{Ti}$ & 167.25 & 943.59 & $1,983.50$ \\
$\mathrm{Co}-\mathrm{Cr}$ & 274.64 & $1,457.00$ & $3,093.80$ \\
$\mathrm{Zr}$ & 312.37 & $1,642.70$ & $3,458.50$ \\
\hline
\end{tabular}

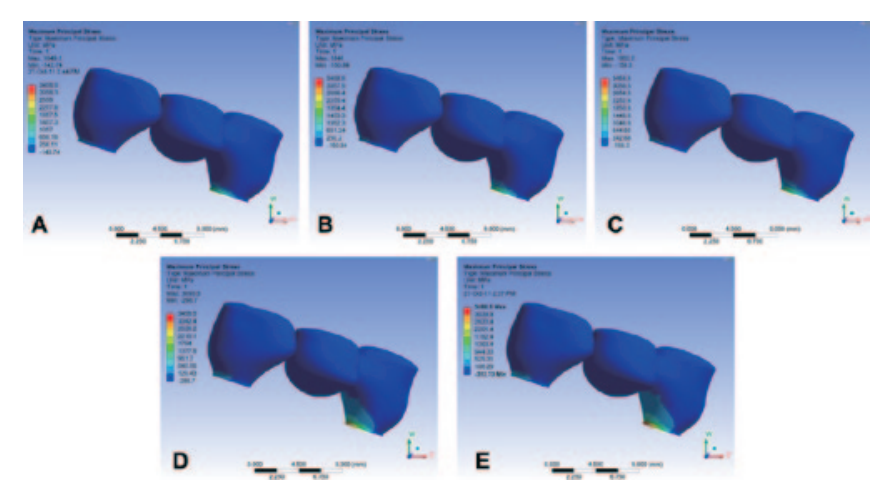

Fig. 2 Maximum Principal Stress distribution in the frameworks with $100 \mu \mathrm{m}$ of vertical misfit: (A) gold type IV alloy, (B) silver-palladium alloy, (C) commercial pure titanium, (D) cobaltchromium alloy, and (E) zirconia.

\section{Framework}

\section{Results}

A significant increase in the maximum principal stress (MPS) values in the frameworks was observed when stiffer materials were evaluated. The increase in the stress values was also proportional to the misfit levels. The higher stress concentrations occurred in the metallic strap of the abutment of the molar, more specifically in the mesial region, where it comes into contact with the implant platform. All the stress values are presented in Table 2. The MPS values in the frameworks with $100 \mu \mathrm{m}$ of vertical misfit are presented in Fig. 2.

\section{Porcelain veneer}

There was a significant decrease in the MPS values in the porcelain veneer when stiffer frameworks were analyzed (Co-Cr and $\mathrm{Zr}$ ). However, the use of less rigid materials (Au, Ag-Pd, and Ti) did not lead to significant differences in the stress distribution. A significant increase in the stress values was observed when the misfit was amplified. As in the frameworks, the maximum stress values were observed in the metallic strap of the abutment of the molar in the mesial region close to the framework interface. All the stress values for the porcelain veneer materials are listed in Table 3. 
Table 3 Maximum principal stress (MPa) in the porcelain veneer

\begin{tabular}{lccc}
\hline \multirow{2}{*}{ Material } & \multicolumn{3}{c}{ Misfit } \\
\cline { 2 - 4 } & $10 \mu \mathrm{m}$ & $50 \mu \mathrm{m}$ & $100 \mu \mathrm{m}$ \\
\hline $\mathrm{Au}$ & 84.68 & 613.09 & $1,376.00$ \\
$\mathrm{Ag}-\mathrm{Pd}$ & 83.17 & 607.30 & $1,368.30$ \\
$\mathrm{Ti}$ & 82.16 & 606.80 & $1,361.00$ \\
$\mathrm{Co}-\mathrm{Cr}$ & 74.27 & 564.26 & $1,243.10$ \\
$\mathrm{Zr}$ & 71.78 & 546.44 & $1,211.60$ \\
\hline
\end{tabular}

Table 4 von Mises stress (MPa) in the screw

\begin{tabular}{lccc}
\hline \multirow{2}{*}{ Material } & \multicolumn{3}{c}{ Misfit } \\
\cline { 2 - 4 } $\mathrm{Au}$ & $10 \mu \mathrm{m}$ & $50 \mu \mathrm{m}$ & $100 \mu \mathrm{m}$ \\
$\mathrm{Ag}-\mathrm{Pd}$ & 7.10 & 35.75 & 71.80 \\
$\mathrm{Ti}$ & 7.38 & 37.14 & 74.59 \\
$\mathrm{Co}-\mathrm{Cr}$ & 7.67 & 38.65 & 77.58 \\
$\mathrm{Zr}$ & 9.18 & 45.97 & 92.17 \\
\hline
\end{tabular}

\section{Retention screw}

The von Mises stress values were recorded in the molar retention screw, and an increase in the values was observed in accordance with the increase of the stiffness of the frameworks. An increase in the stress values in the screw was also observed with misfit amplification. The stresses were observed in the long axis of the screws. The stress values for the screws in the different situations analyzed are presented in Table 4.

\section{Bone stress}

The framework material was shown to have an insignificant influence on the MPS in bone tissue. An increase in stress concentration could be observed with misfit amplification. The cortical bone at the implant-bone interface showed higher stress values. The stress values for the different situations are presented in Table 5. The MPS at all levels of vertical misfit in the cobalt-chromium alloy framework is presented in Fig. 3.

\section{Discussion}

Clinical trials have the potential to provide the strongest evidence. However, in vivo biomechanical measurement is limited by ethical and/or methodological aspects. Thus, finite element analysis (FEA) has been used extensively as a tool of functional assessment in implant research. This methodology consists of a mathematical model that is built based on the prosthesis, implant, and alveolar process geometries, the boundary conditions, and the material properties (Young's modulus and Poisson's
Table 5 Maximum principal stress (MPa) in peri-implant bone

\begin{tabular}{lccc}
\hline \multirow{2}{*}{ Material } & \multicolumn{3}{c}{ Misfit } \\
\cline { 2 - 4 } & $10 \mu \mathrm{m}$ & $50 \mu \mathrm{m}$ & $100 \mu \mathrm{m}$ \\
\hline $\mathrm{Au}$ & 11.49 & 57.25 & 113.90 \\
$\mathrm{Ag}-\mathrm{Pd}$ & 11.93 & 59.43 & 118.26 \\
$\mathrm{Ti}$ & 12.11 & 60.36 & 120.12 \\
$\mathrm{Co}-\mathrm{Cr}$ & 12.19 & 60.71 & 120.78 \\
$\mathrm{Zr}$ & 11.67 & 58.13 & 115.64 \\
\hline
\end{tabular}

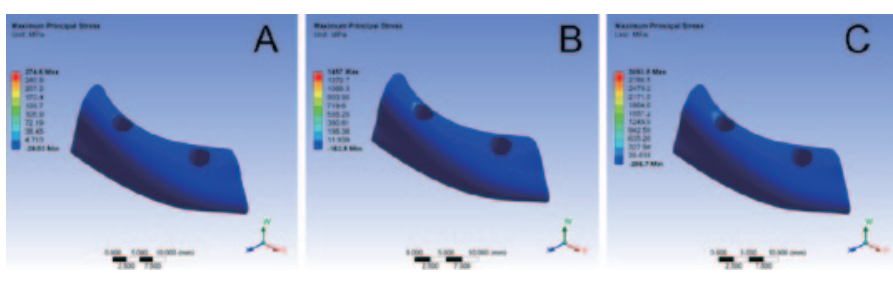

Fig. 3 Maximum principal stress distribution in bone tissue with cobalt-chromium alloy framework in the levels of (A) $10 \mu \mathrm{m}$, (B) 50 $\mu \mathrm{m}$, and (C) $100 \mu \mathrm{m}$ of vertical misfit.

ratio). The implant system performance is measured based on specific values and by a gradient of stress/strain distribution in all structures of the model (23-25).

The model generation and material properties in the present study were modified for simplification. Although all the structures were assumed to be isotropic, homogeneous, and linear elastic, it is known that these conditions do not occur in live tissues, such as the cortical bone, which is transversely isotropic and inhomogeneous (19). The level of osseointegration was considered to be $100 \%$, which has also been demonstrated to be incompatible with real conditions; however, studies have found that the analysis of non-linear frictional contacts and complete osseointegration of the bone-implant interface led to similar results $(26,27)$. The screw and implant thread were removed, as they were found to be irrelevant to the analysis after convergence tests and provided a significant reduction in elements (19).

In the current study, an increase in stress in the retention screw and framework was observed when stiffer materials were used for the prosthesis frameworks. These findings are in agreement with a previous study, which suggested that stiffer framework materials cause higher stress concentrations due to their lesser deformation (11). However, according to the present study, it is possible to infer that this increase in the stress values may not be a clinical problem because the difference in the stresses is lower than the stiffness of the metallic structures. Regarding the retention screws, it has been suggested that the reduced deformation of stiffer frameworks 
during closure of the misfit is responsible for transmitting greater stress to it. Lower stress values in porcelain veneer were observed when stiffer frameworks $(\mathrm{Co}-\mathrm{Cr}$ and $\mathrm{Zr}$ ) were evaluated, which is in agreement with a previous study (20). This can be explained by the fact that, during prosthesis settlement, a less rigid material tends to suffer greater deformation, transferring the stresses to the veneering material. As a result, materials with similar values of elastic modulus ( $\mathrm{Au}, \mathrm{Ag}-\mathrm{Pd}$, and Ti) did not present significant differences in the stress distribution, probably because they have similar deformation capability. The higher stress concentration in the framework and porcelain veneer occurred in the cervical region of the molar crown, more specifically in the mesial region that comes into contact with the implant platform, probably due to the rotational tendency of the prosthesis during closure of the misfit, which causes stress concentration between these structures. The retention screw of the molar presented high stress values, which were observed in the long axis and probably caused by tensile forces.

A considerable increase in stress was observed in the framework, porcelain veneer, and retention screw proportional to the increase in misfit, which is in agreement with previous studies $(8,11,18,21)$. It has been suggested that these structures are more sensitive to a lack of passive fit and are directly responsible for clinical failures such as loosening or fracture of the abutment or prosthetic screw and fracture of the framework or veneers (18) due to asymmetric contact among the various components of the system (28). The association between the vertical misfit and screw loosening has been established by previous studies (29).

In the current study, variation of stiffness of the framework materials did not demonstrate a significant effect on the stress values in the bone tissue surrounding implants, corroborating previous studies $(11,19-21)$. It has also been postulated that the viscoelasticity of bone compensates for any differential rigidity among the prosthetic materials (21). Higher values of MPS were observed in the cortical bone, which can be explained by its higher elastic modulus compared to the cancellous bone (12).

The changes in vertical misfit showed a considerable influence on the stress values in peri-implant bone tissue; this fact was also observed in other FEA reports $(8,17)$. Previous studies performed in primates (9) and rabbits $(10,30,31)$ evaluated the consequences of different levels of vertical misfit on the peri-implant bone tissue. However, these studies had some limitations; it was impossible to evaluate the influence of vertical misfit when under occlusal loads (16) and the consequences in the prosthetic structures, which are important factors in the success of treatment. Other clinical studies have suggested the existence of a certain level of tolerance of bone tissue to a lack of passive fit in implant-supported prostheses. In a previous study, a misfit until $150 \mu \mathrm{m}$ was considered acceptable (6), and in another study, the mean misfit was $111 \mu \mathrm{m}$ and $91 \mu \mathrm{m}$ for 1-year and 5-year follow-up groups, respectively, which did not present a correlation with marginal bone level changes (7). These studies were performed in edentulous patients rehabilitated with full arch prostheses supported by five to seven implants. However, the number of implants and the nature of the prosthesis (full, partial, or single) seem to be important factors in the stress distribution of implantborne prostheses (13). The misfit tolerance observed in full-mouth rehabilitation seems to be unacceptable for partial prosthesis supported by a minimal number of implants.

Based on these considerations, further studies evaluating the influence of occlusal load on the stress distribution in implant-supported partial prostheses are necessary to verify the behavior of ill-fitting prostheses under chewing conditions.

Considering the conditions evaluated in this FEA study, it can be concluded that:

1. Stiffer materials promote higher stress concentration in the framework, which increases proportionally to the stiffness of the materials.

2. Stiffer frameworks increase the stress values in the retention screw, while in the same circumstances, the porcelain veneer shows lower stress values.

3. The stiffness of the materials does not have a significant effect on the stresses in peri-implant bone tissue.

4. A considerable increase in stress concentration was observed in all structures (framework, porcelain veneer, retention screw, and peri-implant bone) when the misfit was increased.

\section{References}

1. Pietrabissa R, Contro R, Quaglini V, Soncini M, Gionso L, Simion M (2000) Experimental and computational approach for the evaluation of the biomechanical effects of dental bridge misfit. J Biomech 33, 1489-1495.

2. Abduo J, Bennani V, Waddell N, Lyons K, Swain M (2010) Assessing the fit of implant fixed prostheses: a critical review. Int J Oral Maxillofac Implants 25, 506-515.

3. Brånemark PI (1983) Osseointegration and its experimental background. J Prosthet Dent 50, 399-410. 
4. Schwarz M (2000) Mechanical complications of dental implants. Clin Oral Implants Res 11, Suppl 1, 156-158.

5. Sahin S, Cehreli M, Yalçin E (2002) The influence of functional forces on the biomechanics of implant-supported prostheses - a review. J Dent 30, 271-282.

6. Jemt T (1991) Failures and complications in 391 consecutively inserted fixed prostheses supported by Brånemark implant in edentulous jaw: a study of treatment from the time of prostheses placement to the first annual check-up. Int J Oral Maxillofac Implants 6, 270-276.

7. Jemt T, Book K (1996) Prosthesis misfit and marginal bone loss in edentulous implant patients. Int J Oral Maxillofac Implants 11, 620-625.

8. Kunavisarut C, Lang LA, Stoner BR, Felton DA (2002) Finite element analysis on dental implant-supported prostheses without passive fit. J Prosthodont 11, 30-40.

9. Carr AB, Gerard DA, Larsen PE (1996) The response of bone in primates around unloaded dental implants supporting prostheses with different levels of fit. J Prosthet Dent 76, 500-509

10. Michaels GC, Carr AB, Larsen PE (1997) Effect of prosthetic superstructure accuracy on the osteointegrated implant bone interface. Oral Surg Oral Med Oral Pathol Oral Radiol Endod 83, 198-205

11. Abreu RT, Spazzin AO, Noritomi PY, Consani RLX, Mesquita MF (2010) Influence of material of overdenture-retaining bar with vertical misfit on three-dimensional stress distribution. J Prosthodont 19, 425-431.

12. Meriç G, Erkmen E, Kurt A, Tunç Y, Eser A (2011) Influence of prosthesis type and material on the stress distribution in bone around implants: a 3-dimensional finite element analysis. J Dent Sci 6, 25-32

13. Brunski JB (1992) Biomechanical factors affecting the bonedental implant interface. Clin Mater 10, 153-201.

14. Erkmen E, Meriç G, Kurt A, Tunç Y, Eser A (2011) Biomechanical comparison of implant retained fixed partial dentures with fiber reinforced composite versus conventional metal frameworks: a 3D FEA study. J Mech Behav Biomed Mater 4, 107-116.

15. Sahin S, Cehreli MC (2001) The significance of passive framework fit in implant prosthodontics: current status. Implant Dent 10, 85-92.

16. Natali AN, Pavan PG, Ruggero AL (2006) Evaluation of stress induced in peri-implant bone tissue by misfit in multi-implant prosthesis. Dent Mater 22, 388-395.

17. Winter W, Mohrle S, Holst S, Karl M (2010) Bone loading caused by different types of misfits of implant-supported fixed dental prostheses: a three-dimensional finite element analysis based on experimental results. Int J Oral Maxillofac Implants 25, 947-952.

18. Spazzin AO, Abreu RT, Noritomi PY, Consani RL, Mesquita MF (2011) Evaluation of stress distribution in overdentureretaining bar with different levels of vertical misfit. J Prosthodont 20, 280-285.
19. Sevimay M, Usumez A, Eskitascioglu G (2005) The influence of various occlusal materials on stresses transferred to implant-supported prostheses and supporting bone: a threedimensional finite-element study. J Biomed Mater Res B Appl Biomater 73, 140-147.

20. Sertgöz A (1997) Finite element analysis study of the effect of superstructure material on stress distribution in an implantsupported fixed prosthesis. Int J Prosthodont 10, 19-27.

21. Assunção WG, Gomes EA, Barão VA, Delben JA, Tabata LF, de Sousa EA (2010) Effect of superstructure materials and misfit on stress distribution in a single implant-supported prosthesis: a finite element analysis. J Craniofac Surg 21, 689-695.

22. Juodzbalys G, Kubilius R, Eidukynas V, Raustia AM (2005) Stress distribution in bone: single-unit implant prostheses veneered with porcelain or a new composite material. Implant Dent 14, 166-175.

23. Geng JP, Tan KB, Liu GR (2001) Application of finite element analysis in implant dentistry: a review of the literature. J Prosthet Dent 85, 585-598.

24. Van Staden RC, Guan H, Loo YC (2006) Application of the finite element method in dental implant research. Comput Methods Biomech Biomed Engin 9, 257-270.

25. Bacchi A, Consani RL, Mesquita MF, dos Santos MB (2012) Influence of different mucosal resiliency and denture reline on stress distribution in peri-implant bone tissue during osseointegration. A three-dimensional finite element analysis. Gerodontology 29, e833-837.

26. Papavasiliou G, Kamposiora P, Bayne SC, Felton DA (1997) 3D-FEA of osseointegration percentages and patterns on implant-bone interfacial stresses. J Dent 25, 485-491.

27. Ding X, Zhu XH, Liao SH, Zhang XH, Chen H (2009) Implant-bone interface stress distribution in immediately loaded implants of different diameters: a three-dimensional finite element analysis. J Prosthodont 18, 393-402.

28. Gomes EA, Assunção WG, Tabata LF, Barão VA, Delben JA, de Sousa EA (2009) Effect of passive fit absence in the prosthesis/implant/retaining screw system: a two-dimensional finite element analysis. J Craniofac Surg 20, 2000-2005.

29. Bacchi A, Paludo L, Mesquita MF, Schuh C, Federizzi L, Spazzin AO (2013) Loosening torque of prosthetic screws in metal-ceramic or metal-acrylic resin implant-supported dentures with different misfit levels. J Biomech 46, 13581362.

30. Jemt T, Lekholm U, Johansson CB (2000) Bone response to implant-supported frameworks with differing degrees of misfit preload: in vivo study in rabbits. Clin Implant Dent Relat Res 2, 129-137.

31. Duyck J, Vrielinck L, Lambrichts I, Abe Y, Schepers S, Politis $\mathrm{C}$ et al. (2005) Biologic response of immediately versus delayed loaded implants supporting ill-fitting prostheses: an animal study. Clin Implant Dent Relat Res 7, 150-158. 